\title{
Genomic diversification of enterococci in hosts: the role of the mobilome
}

\section{Maria Santagati, Floriana Campanile and Stefania Stefani *}

Molecular Microbiology and Antibiotic Resistance Lab, Department of Microbiology, University of Catania, Catania, Italy

\section{Edited by:}

Jose L. Martinez, Centro Nacional de

Biotecnología, Spain

\section{Reviewed by:}

Jose L. Martinez, Centro Nacional de

Biotecnología, Spain

Teresa M. Coque, Hospital

Universitario Ramón y Cajal, Spain

*Correspondence:

Stefania Stefani, Department of Microbiology, University of Catania, Via Androne 81, 95124 Catania, Italy. e-mail:stefanis@unict.it

\begin{abstract}
Enterococci are ubiquitous lactic acid bacteria, possessing a flexible nature that allows them to colonize various environments and hosts but also to be opportunistic pathogens. Many papers have contributed to a better understanding of: (i) the taxonomy of this complex group of microorganisms; (ii) intra-species variability; (iii) the role of different pathogenicity traits; and (iv) some markers related to the character of host-specificity, but the reasons of such incredible success of adaptability is still far from being fully explained. Recently, genomic-based studies have improved our understanding of the genome diversity of the most studied species, i.e., E. faecalis and E. faecium. From these studies, what is becoming evident is the role of the mobilome in adding new abilities to colonize new hosts and environments, and eventually in driving their evolution: specific clones associated with human infections or specific hosts can exist, but probably the consideration of these populations as strictly clonal groups is only partially correct. The variable presence of mobile genetic elements may, indeed, be one of the factors involved in the evolution of one specific group in a specific host and/or environment. Certainly more extensive studies using new high throughput technologies are mandatory to fully understand the evolution of predominant clones and species in different hosts and environments.
\end{abstract}

Keywords: enterococci, population analysis, antibiotic resistance, genomic, mobile genetics elements, host specificity, E. faecalis, E. faecium

\section{THE GENUS ENTEROCOCCUS}

The genus Enterococcus contains bacterial species that are ecologically diverse. They are Gram-positive lactic acid bacteria that are found in the gastrointestinal consortia of humans, other mammals, reptiles, amphibians, birds, and insects and are used in the production of fermented foods and probiotics (Benno et al., 1992; Aarestrup et al., 2002; Tannock and Cook, 2002). To date, only species from humans and domestic animals have been studied in some detail.

Enterococci have gained notoriety over the past few decades as frequent causes of hospital-acquired infection at extra-intestinal sites, including surgical site wounds, urinary tract, and heart. The ability of these microorganisms to cause infections has been linked to the intrinsic ruggedness of these species, which allows the organism to persist in the hospital environment and survive many host defenses compounded by the acquisition of a variety of variable virulence and resistance traits by horizontal transfer from other organisms: being rugged and genetically flexible is an important feature of these microorganisms (Fisher and Phillips, 2009; Palmer et al., 2010b; Laverde Gomez et al., 2011a).

Enterococci are among the most antibiotic-resistant bacterial pathogens known. For reasons not well understood, they appear to have served as a key collection point for a wide variety of antibiotic-resistance determinants. It is well known that enterococci possess the intrinsic low-level resistance to cephalosporins, some beta-lactam antibiotics and about $83 \%$ of clinical isolates of E. faecium show the high levels of resistance due to the presence of an alternative penicillin-binding protein (PBP5), and aminoglycosides. In addition, the acquired high-level resistance to beta-lactams, aminoglycosides, and glycopeptides is associated with the acquisition of foreign DNA mediated by lateral gene transfer (LTG; Shepard and Gilmore, 2002). It was recently shown that enterococci have transferred vancomycin resistance to methicillinresistant Staphylococcus aureus, and the opposite transfer from Staphylococcus to Enterococcus clinical strains has also been documented (Weigel et al., 2003; Perichon and Courvalin, 2004; Sarti et al., 2012).

The genus Enterococcus, after different taxonomical allocations that have identified more than 40 different species (http://www.bacterio.cict.fr/enterococcus.html), has retained 17 species: formal infra-species division has not been made in the genus, though some ecovar-related variability has become apparent in E. faecium. These ecovars pertain to biochemical reaction types (biotypes) and, in some cases, they have been found to be host associated: example are raffinose-positive $E$. faecium in poultry and sorbitol-positive E. faecium found in dogs; but more convincingly, some genotypes have been associated with certain animal host species (Devriese et al., 1994; Quednau et al., 1998). Association of some genogroups with different hosts has been recently found in a group of vancomycin-resistant E. faecium (VRE) isolated from hospitalized, non-hospitalized patients, and different animal sources, by using AFLP analysis (Willems et al., 2000). The Authors, in this subgroup of strains, also demonstrated that various pig strains were indistinguishable from human strains.

Among these 17 species, E. faecalis and E. faecium are mainly isolated from human infections: a few years ago, the proportion 
between the two species was $80-90 \%$ for E. faecalis and $5-12 \%$ for E. faecium (Cetinkaya et al., 2000). In recent years, the emergence of enterococci has been associated with a gradual replacement of $E$. faecalis (responsible for approximately $40 \%$ of enterococcal infections) with E. faecium (more than $60 \%$ of these infections) probably because of the rapid accumulation of antibiotic-resistance determinants in this latter species (Iwen et al., 1997; Treitman et al., 2005; Top et al., 2007; Hidron et al., 2008).

\section{HABITAT}

The best known, though not the only habitat of the enterococci, is the gut of mammals and birds; they may be a significant component of other animal groups as well. Most enterococcal species known to date are typically associated with the intestine of humans and domestic animals, and when found outside the gut, they are interpreted as indicators of fecal pollution or, in the case of the human body, as possible pathogens. Some species, i.e., E. casseliflavus, E. mundtii, and E. sulfureus appear to have adapted to vegetative life in environmental habitats and can colonize plants (Klein, 2003). A recent study demonstrated single E. casseliflavus populations in submerged aquatic vegetation and the Authors concluded that this species represents a naturalized reproducing indicator bacteria, not directly related to pollution events (Badgley et al., 2010).

As stated before, E. faecalis and E. faecium are the most common isolates in the human gastrointestinal tract: the number of $E$. faecalis in human feces range from $10^{5}$ to $10^{7}$ per gram and those of E. faecium from $10^{4}$ to $10^{5}$ per gram (Tannock and Cook, 2002; Fisher and Phillips, 2009).

Taking into consideration different species, there are certain variations depending on different factors: host, age, and feeding behavior. For example, E. faecalis and E. faecium occur predominantly in humans; E. cecorum is a member of the enterococcal flora of pigs and poultry; E. hirae is a frequent inhabitant of the porcine gut and may occur in poultry, cattle, dogs, and cats, $E$. asini that is specific for donkeys (Aarestrup et al., 2002). Furthermore, enterococcal colonization takes place more during the very first period of life, and varies depending on intestinal compartment, and on type of feeding (Vaughn et al., 1979; Collins et al., 1986).

E. faecalis and E. faecium are also regularly isolated from cheese, fish, sausages, minced beef, and pork (Fontana et al., 2009; NietoArribas et al., 2011). In some cases these species are involved in food spoilage and fermentation; in others (above all when they are isolated from food of animal origins) they are often associated with contamination due to their ability to survive the heating process (Fisher and Phillips, 2009).

Some E. faecium and E. faecalis strains are used as probiotics and are then ingested at high inocula. Such probiotics are used to treat various dysbiosis (antibiotic-associated diarrhea or irritable bowel syndrome), to lower cholesterol or to improve host immunity (Franz et al., 2011). All these benefits were assessed and confirmed by practical use and, recently, in an animal model (Tarasova et al., 2010), but in view of the emergence of problematic enterococcal lineages and the potential for gene transfer in the gastrointestinal tract of both human and animals, their use needs to be carefully monitored (Franz et al., 2011).
In conclusion, it is evident that enterococci are able to colonize a variety of niches due to their ability to survive in a wide range of environmental conditions.

\section{NOSOCOMIAL PATHOGENS AND MULTI-DRUG RESISTANCE}

Enterococci are known to be causes of endocarditis and rare cases of meningitis. However, this picture has changed dramatically over the last 20 years, in which enterococci have become one of the leading causes of nosocomial infections and - according to the recent National Nosocomial Infection Surveillance (NNIS) surveys (NNIS, 2004; Rosenthal et al., 2008) - they remain in the top three most common pathogens responsible for urinary tract, intraabdominal, pelvic, surgical, wound, and central venous catheter (CVC) associated infections and bacteremia, which may seed to more distant sites. For example, genitourinary tract infections or instrumentation use often precedes the onset of enterococcal endocarditis. Pleural space infections, as well as skin and soft tissue infections, have also been reported (Rice et al., 2004; Deshpande et al., 2007).

Hospital-associated enterococcal infections emerged differently in the USA with respect to Europe (around 1990) and concurrently with the acquisition of vancomycin resistance. Even if with a different percentage of isolation, vancomycin resistance in Europe has so far not spread to hospitals at the same levels as in the USA (there are, in any case, variations among European countries with some, such as Greece and Ireland, having rates exceeding 30\%, while Italian and Spanish prevalence is less than $5 \%$, Germany less than $10 \%$, and the UK with approximately $13 \%$; Werner et al., 2008). In general, most E. faecium isolates recovered from hospitalized patients are more resistant to antimicrobial agents than community-derived isolates. In particular ampicillin and fluoroquinolone resistance are important markers that distinguish hospital from community-derived isolates (Coque et al., 2005; Willems et al., 2005; Willems and van Schaik, 2009).

\section{PATHOGENIC ENTEROCOCCI}

In general, the virulence of enterococci is lower than that of other organisms such as $S$. aureus. However, enterococcal infections often occur in debilitated patients and as a part of polymicrobial infections: these factors limit the ability of investigators to determine the independent contribution of enterococcal infections to mortality and morbidity.

Perturbation in the dynamics of the host/commensal relationship is related to different causes: (i) the access to extra-intestinal sites can be promoted by antibiotic-treatment, host injury, or diminished host immunity; and (ii) the transition from a commensal behavior to a pathogen happens through the acquisition of new traits. The latter has been gaining ground after the identification of pathogenicity islands (PAI) in E. faecalis (Shankar et al., 2002). These elements encode several genetic determinants involved in colonization and virulence, and possess modular structures able to adapt their genetic content, with the acquisition or loss of pathogenicity factors. Diverse PAI variants are widely distributed among enterococcal strains belonging to various clonal complexes $\left(\mathrm{CC}_{\mathrm{s}}\right)$, origins, and hosts, which enrich their accessory genomes with new traits able to enhance their pathogenicity in hospitalized patients (McBride et al., 2009). The spread of 
these more infective clones is mainly due to the presence of factors involved in colonization and ability to form biofilm, the first crucial steps in clinical infection and nosocomial spread of antibiotic-resistant strains.

In E. faecalis, some of the most prominent virulence determinants and factors involved in colonization and biofilm formation are: a secreted toxin cytolysin; a collagen-binding adhesin of the microbial surface component recognizing adhesive matrix molecules (MSCRAMM-ACE); an adhesin expressed on the surface of the bacteria designated Esp (proteins associated with virulence, initially found only in hospital-derived strains, and now variably present in some animal isolates); an autolysin (Atn formerly AtlA); a sugar-binding transcriptional regulator (BopD); a secreted proteases gelatinase (GelE); a cell-anchored protein (Bee); and a sortase associated to surface pili formation (Ebp; Singh et al., 1998, 2005; Rich et al., 1999; Eaton and Gasson, 2002; Hufnagel et al., 2004; Mohamed et al., 2004; Shankar et al., 2004; Tendolkar et al., 2006; Schluter et al., 2009; Heikens et al., 2011; Nallapareddy et al., 2011; Pinkston et al., 2011).

It has been ascertained that E. faecalis is more virulent than E. faecium. Even if in the past E. faecium have been less studied, recently various aspects regarding its virulence and pathogenicity have examined. A glycosyl hydrolase, encoded by the $h y l_{\mathrm{Efm}}$ gene, has been hypothesized to be involved in infections of hospitalassociated E. faecium, but a recent study performed on a murine peritonitis E. faecium model, did not show any in vivo effect on virulence (Willems et al., 2001; Woodford et al., 2001; Coque et al., 2002; Rice et al., 2003; Leavis et al., 2004; Panesso et al., 2011). Recently, the group of Murray demonstrated the involvement of two $g l s$-loci in the adaptation to the intestinal environment and virulence, in response to the in vitro bile salts stress, and the presence of the $e b p A B C_{f m}$ locus encoding pili, in E. faecium TX82, confirming their role in pathogenicity and biofilm formation (Sillanpää et al., 2010; Choudhury et al., 2011). As in E. faecalis, the role of Esp in forming biofilm has been demonstrated also in $E$. faecium (Sava et al., 2010).

It is clear that the presence of a specific virulence trait can not be always considered predictive of pathogenicity in itself: complex interactions between these and other traits, as well as host and environmental conditions, can influence microbial behavior; in this context, the study of key regulators of gene expression is of great importance, such as the recent identification of small RNAs (sRNA) as mediators of virulence and stress inducible gene expression, in E. faecalis V583 (Shioya et al., 2011).

\section{KNOWLEDGE ON POPULATION BIOLOGY OF DRUG-RESISTANT ENTEROCOCCI FROM HOSPITAL AND NON-HOSPITAL ORIGINS}

Many studies published in recent years have indicated that hospital-derived strains have acquired traits involved in resistance and pathogenesis (Baldassarri et al., 2001; Willems et al., 2001; Woodford et al., 2001). These studies have recently been supported by more global experimental designs able to give a more complete perspective.

We report here results of different studies aiming to improve our understanding on the population biology diversity of enterococci isolated from different hosts.
A recent comparative genomic hybridization study using a mixed whole genomic array (Leavis et al., 2007) on strains of E. faecium isolated from various genetic and ecological backgrounds, demonstrated that: (i) hospital-derived isolates were grouped together; and (ii) IS elements together with resistance genes, genes encoding novel metabolic pathways, genes encoding membrane proteins and regulatory genes, were more that $80 \%$ specifically associated. Furthermore, in MLST-based studies, antibiotic-resistant strains that cause infections clustered into distinct groups with respect to strains colonizing the gastrointestinal tract of healthy individuals in the community (Willems and van Schaik, 2009). As stated before, in addition to possessing resistances to multiple antibiotics such as vancomycin, enterococcal strains often possess a set of genes that contribute to virulence (van Schaik and Willems, 2010). Potential virulent strains can also arise in the same clonal complex (CC), due to the acquisition of virulence factors carried by PAI elements, that could contribute to change commensal E. faecalis strains into pathogenic ones, to confer and increase their ability to colonize different gastrointestinal tract niches (Coburn et al., 2007; Willems and van Schaik, 2009).

Even if only few lineages/clonal complexes $\left(\mathrm{CC}_{\mathrm{s}}\right)$ of $E$. faecium and E. faecalis have been currently associated with hospital outbreaks, the large number of resistance and colonization traits harbored in hospital isolates suggests consecutive cumulative gene acquisition, integration and successful adaptation to these new conditions (Baquero, 2004; Leavis et al., 2007; McBride et al., 2007).

Several other recent studies have demonstrated that hospitalacquired isolates clustered in few clonal complexes - CC2 and CC9 in E. faecalis and CC17 in E. faecium - these have also been recovered from farm animals and pets; moreover, strains belonging to CCs commonly found among animals have also been isolated from humans (E. faecium CC5, E. faecalis CC16 or CC21; Leavis et al., 2006a; Biavasco et al., 2007; Damborg et al., 2009; Freitas et al., 2009a,b; Willems and van Schaik, 2009; Larsen et al., 2010).

Many enterococcal strains from human and swine hosts - all vancomycin-resistant (VRE) - showed different STs (clustering mainly in E. faecium CC17 and CC5, and E. faecalis CC2), harbored Tn1546 on indistinguishable plasmids (Freitas et al., 2011). In surveillance studies performed in Portugal, Denmark, Spain, Switzerland, and the United States from 1995 to 2008, a sample of VRE isolates from pigs and healthy people was compared with outbreak/prevalent VRE clinical strains (isolated from 23 countries in the same period). This study demonstrated intra- and inter-national diffusion of E. faecium and E. faecalis strains showing the same CCs and plasmids among swine and humans (Freitas et al., 2011).

In another MLST-based study in which ampicillin-resistant E. faecium isolates from dogs and humans were compared, the widespread occurrence of hospital-associated lineages in dogs was demonstrated (Damborg et al., 2009) and two of them, i.e., ST78 and ST192 are among the most common lineages causing infections in European and Asian hospitals (Ko et al., 2005; Bonora et al., 2007; Werner et al., 2007; Top et al., 2008). The knowledge of the host-specificity of E. faecium and E. faecalis genetic backgrounds that cluster according to the species of origin was not confirmed here, indicating that dogs may play a role in the 
spread of this nosocomial pathogen (Willems et al., 1999, 2000; Leavis et al., 2006a; Damborg et al., 2009). Damborg et al. (2009) demonstrated that what distinguished canine from human isolates were the virulence and antimicrobial resistance profiles observed: those strains causing human infections were MDR and virulent bacterial populations, despite the genetic similarities observed.

The above mentioned ST78 and ST192, together with ST19, ST117, 202 and 18 - all included in the hospital-associated CC17 were also the first beta-lactamase producing E. faecium recently isolated in Italy (Sarti et al., 2011; Sarti et al., 2012. Analyzing MLST data from deposited E. faecium sequences and making a comparison with beta-lactamase producing strains, belonging to different PFGE, a clear ST clustering of hospital isolates together with isolates from dogs and cats and, less frequently, with non-hospital strains, was found (data not shown; Sarti et al., 2011).

As reported before, dogs can be frequent carriers of CC17related lineages, in particular ST78 and ST192 and the human microbiota can indeed be an excellent hot-spot of recombination for the transfer of resistance mechanisms, including beta-lactams (Damborg et al., 2009). Even if mechanisms of the ecological dominance of these CC17 hospital-acquired E. faecium strains are not well understood, there are hypotheses that the acquisition of antibiotic-resistance traits, together with cell-surface proteins, may have contributed to their success (Leavis et al., 2006b; Heikens et al., 2008).

\section{ENTEROCOCCAL GENOMES AND GENOME-BASED STUDIES}

Enterococcal genome sequences still remain relatively limited, especially for E. faecium strains, making difficult the understanding of their fundamental biology and virulence-associated traits, when compared to E. faecalis.

The sequencing of the E. faecalis V583 genome was undertaken in the late 1990s and completed in 2002, and revealed a large content of PAI, mobile genetic elements (MGE) and plasmids carrying antibiotic-resistance determinants, but lacked the esp and $c y l$ genes because a 17-kb DNA fragment carrying these genes had been excised from the PAI itself (Paulsen et al., 2003). The sequencing of the V583 genome appeared to provide new insight into enterococcal genomes, into their genetic makeup and biology. Unfortunately, since then only two other E. faecalis genome sequences have been published (OG1RF and EF62), for which the publicly available genome sequence is not completely annotated, reducing their usefulness as a starting-point for genome-wide studies (Bourgogne et al., 2008). With regard to E. faecalis EF62, this strain was isolated in a healthy Norwegian infant in 2006 and belonged to CC6, which had never been associated with nosocomial infections. In this genome, the presence of genomic islands (GIs) carrying genes involved in lactose and other carbohydrate metabolisms instead of virulence determinants, emphasized its adaptation to its commensal existence (Solheim et al., 2011).

In 2007, a partial genome analysis of the commercial probiotic strain E. faecalis Symbioflor (Symbiopharm, Herborn, Germany) was made; this strain does not possess any virulence determinants, and for this reason was proposed as a probiotic, but no information was available due to the absence of sequence data for this strain (Domann et al., 2007).
Even less sequence information is available for E. faecium, making it the only major nosocomial pathogen for which no complete genome sequence is publicly available. In fact, the E. faecium strain TX0016 genome sequence (Acc. No. ACIY00000000); (formerly E. faecium DO strain, isolated in 1992 from a case of endocarditis), already announced in 2000, has not yet been finished (van Schaik and Willems, 2010). Furthermore, annotations regarding genes encoding essential products - such as ribosomal proteins - are missing, indicating an incomplete assembly.

Recently, van Schaik et al. (2010) have undertaken a genome sequencing project of seven E. faecium strains, isolated from different ecological niches in different periods, using pyrosequencing technology, to partially resolve the current lack of genomic information on this species. Briefly, their conclusions can be summarized in three important messages: (i) hospital-associated isolates accumulate genomic differences related to antibiotic resistance and colonization genes; (ii) strains belonging to the same CC, i.e., CC17, are closely related in the core genome, but still have a large difference in the gene content; and (iii) the pan-genome analysis of E. faecium indicated that the total available gene pool within this species is essentially unlimited, depending on the ecological niches that this species can colonize. The gain and/or loss of MGEs, rather than evolutionary descent, is the most important driving force in enterococci.

In addition to this, an interesting report was published in 2010, in which the draft genome sequences for 28 enterococcal strains of diverse origin, including the species E. faecalis, E. faecium, Enterococcus casseliflavus, and Enterococcus gallinarum, were analyzed. These new data could possibly fill the gap in enterococcal genome data and provide new insights into basic enterococcal physiology (Palmer et al., 2010a).

All these published genome-based studies of enterococci have contributed to our understanding of genomic diversity, especially in E. faecalis and E. faecium, confirming the affirmation of specific sub-populations associated with humans, which possess large differences in their accessory genes, including MGEs, making them an important factor in phenotypic characteristics.

Comparative and genome hybridization studies published so far are going in the same direction as previous studies, that enterococcal diversity depends on a considerable inter-strain genomic diversity due to genetic exchange, which is mainly linked to the variable presence of phages, plasmids, PAI, and conjugative elements. A recently described mechanism of PAI movement by plasmid integration, due to a pheromone-responsive plasmid as mediator of genome plasticity, was described in E. faecalis. The Authors observed that the amount of transferred chromosome varied considerably, mainly when the V583 genome was used as donor chromosome from which the largest transfer (over 25\%) was obtained. Traits that were mobilized into the E. faecalis OG1RF recipient included a capsule locus, a vancomycin-resistance transposon, the PAI, and even MLST markers, creating a double locus variant of the parental strain in a single event (Manson et al., 2010).

In a recent study, the differences and identities among $16 \mathrm{E}$. faecalis draft genome sequences were correlated to the location and content of "Clustered, regularly interspaced short palindromic repeats" (CRISPR) loci (Palmer and Gilmore, 2010). CRISPR loci have been shown in Bacteria and Archaea to confer resistance 
to plasmid and phage entry, in a manner analogous to acquired immunity. This immunity depends on the presence of specific target-derived spacer sequences, the intervening repeat palindromes, and nuclease activity encoded by the cas genes (Barrangou et al., 2007; Marraffini and Sontheimer, 2008, 2010; Horvath and Barrangou, 2010). The comparison of the genomic sequence of E. faecalis OG1RF and E. faecalis V583, revealed that the former possesses two CRISPR loci - a CRISPR locus carrying their cas genes (CRISPR1-cas), and an orphan locus lacking cas genes (CRISPR2) - differing from the latter, which showed only the orphan CRISPR2 locus, and lacking CRISPR1-cas. (Barrangou et al., 2007; Marraffini and Sontheimer, 2008, 2010; Horvath and Barrangou, 2010).

In E. faecalis V583, the absence of CRISPR-cas may have reduced the barrier to entry of foreign elements, resulting in the convergence and accumulation of 6 plasmids or plasmid remnants, 7 phage or phage remnants, and over 40 IS elements, while OG1RF natively lacks plasmids (McBride et al., 2007; Bourgogne et al., 2008). The same Authors also found a highly significant inverse relationship between the presence of a CRISPR-cas locus and acquired antibiotic resistance in E. faecalis and similarly in additional 8 genomes, suggesting that antibiotic use inadvertently selects for enterococcal strains with compromised genome defense (Palmer and Gilmore, 2010). It is interesting that no CRISPR spacers have yet been identified with sequence identity to conjugative transposons such as Tn916 and, in a similar manner, spacers targeting the Inc18 plasmid family, with the "crucial" role in the dissemination of vancomycin-resistance genes from enterococci to MRSA are also absent (Sieradzki et al., 1999; Tenover et al., 2001; Srinivasan et al., 2002; Chang et al., 2003; Malachowa and DeLeo, 2010; de Niederhausern et al., 2011). In all these cases it has been possible to hypothesize that these elements may evade the CRISPR-cas system defense.

A recent paper of van Schaik et al. (2010) has demonstrated the lack of the CRISPR-cas in 7 pyrosequenced-based E. faecium genome analyses.

\section{DOES THE MOBILOME DRIVE THE CHANGE?}

The mobilome, defined as all MGEs able to move around within or between genomes, contributes to genome plasticity as well as dissemination of antibiotic-resistance genes and pathogenicity. For our purposes here, for example in E. faecalis V587, mobile elements, that constitute one-quarter of its genome, include three independently replicating plasmids, three chromosomally integrated plasmid remnants, seven prophages, and a PAI (Shankar et al., 2002; Paulsen et al., 2003). It has been also reported that the acquisition of exogenous DNA could be involved in the conversion from a commensal to a pathogenic behavior in E. faecium (Willems and van Schaik, 2009).

The E. faecium strains belonging to CC17, are similarly characterized by an abundance of exogenously acquired genes, including insertion sequences, phages, and antibiotic-resistance genes carried on transposons (Leavis et al., 2007).

In this respect, the first CTn (conjugative transposon), Tn916, was originally discovered in the late 1970s in E. faecalis when tetracycline resistance was demonstrated to be transferable from E. faecalis DS16 to E. faecalis JH2-2. Tn916 belongs to the
Tn916/Tn1545 family and contains 24 ORFs involved in conjugal transfer, excision, integration, and antibiotic resistance. This genetic element has an extraordinary ability to acquire accessory genes such as resistance genes to various antibiotics or lantibiotic immunity, and it is able to transfer onto over 35 different genera of bacteria. For all these reasons, Tn916-like elements assume a pivotal role as vectors in the dissemination of various traits among environmental, commensal, and pathogenic bacteria (Roberts and Mullany, 2009).

After the emergence of enterococcal antibiotic resistance to beta-lactams and aminoglycosides in the 1980s, the first reports on vancomycin resistance in hospital isolates in Europe (Uttley et al., 1988) were very disturbing; but more disturbing was the detection of this resistance outside health-care settings, and precisely in the feces of pigs, poultry, and pets in Europe, for the first time, in 1993, inducing the European Union to ban glycopeptide use as a growth promoter in animals (Bates et al., 1994; Klare et al., 1995; Bates, 1997; van den Bogaard et al., 2000).

Resistance to glycopeptides in enterococci is mediated by nine different vancomycin-resistance determinants, but major vancomycin-resistance phenotypes are VanA and VanB (Courvalin, 2006; Boyd et al., 2008; Lebreton et al., 2011). The former is associated with $\operatorname{Tn} 1546$ carrying the vanA gene, often located on a plasmid belonging to the broad host range Inc18 family, involved in the vanA transfer from enterococci to MRSA; while the $v a n \mathrm{~B}$ operon, carried by the $\operatorname{Tn} 1549$ conjugative transposon, can be frequently part of large conjugative chromosomal elements or integrated in conjugative plasmids. More recently, the first description of a vanB2-Tn1549-like element in pheromone-responsive (pCF10-like) plasmids in E. faecalis strains has been reported. This transfer was mediated by a single event, resulting in the contemporary acquisition of: (i) the conjugative transposon Tn1549 carrying the vanB2-type gene; (ii) genes involved in the pheromone-response of self-transferable plasmids; and (iii) the origin of plasmid transfer (oriT; Zheng et al., 2009; Hegstad et al., 2010). In addition, Tn1546 has undergone a large number of changes in VRE and a total of 22 different Tn1546-like elements have been identified: they can contain mutations, deletions or insertions of IS (IS1216V, IS 1251, IS1216V-IS3-like, ISEf1; Novais et al., 2008; Werner et al., 2008).

Composite multi-resistance elements have also been described: among them, Tn5385 is a $65-\mathrm{kb}$ element integrated into the chromosome of a clinical E. faecalis, carrying genes involved in erythromycin, streptomycin, tetracycline/minocycline, penicillin, and mercury resistance. This composite element contains regions previously found in staphylococcal and enterococcal transposons: Tn5381 and Tn5385 from enterococci and Tn4001 and Tn552 from staphylococcal origin, carrying respectively aminoglycosides (aacA-aphD) and beta-lactams (blaI-blaR1-blaZ; Rice and Carias, 1998).

Plasmids are abundant in enterococci and they comprise a substantial part of the auxiliary genome: they are responsible for much of the horizontal gene transfer that has allowed antibiotic and virulence traits to converge in hospital adapted lineages (Palmer et al., 2010b; Rosvoll et al., 2010). The pheromone-responsive plasmids have been described mainly in E. faecalis (Palmer et al., 2010b; 
Laverde Gomez et al., 2011a,b). pAD1, and subsequently, pCF10 were the first plasmids to be described with pheromone-mediated transfer, even between different species (Dunny et al., 1978, 1981; An and Clewell, 1997).

Recent studies described the location of hyl $\mathrm{Efm}_{\mathrm{Em}}$ gene in association with other resistance determinants such as the vanA operon, the ermB gene and the $\operatorname{tcr} Y A Z B$ operon (heavy metal resistance) in a large conjugative plasmids, pLG1 (281.02 kb) in E. faecium CC17. The hyl $l_{\text {ffm }}$ gene, encoding a putative hyaluronidase, an important factor involved in colonization and adhesion, is also described as a part of a genomic island (GI). The diffusion of a multi-resistant megaplasmid pLG1 carrying hyl $\mathrm{Efm}_{\mathrm{fm}}$ could explain the diffusion of the so frequent hospital-associated E. faecium CC17 genotype (Freitas et al., 2010; Kim et al., 2010; Laverde Gomez et al., 2011b; Panesso et al., 2011).

\section{CONCLUSION}

In conclusion, population biology and genome sequence-based studies have greatly improved our understanding on enterococci, at least with respect to the most diffused and studies species, i.e., E. faecalis and E. faecium.

Even if not conclusive and not valid for all species, from the numerous studies involving strains isolated from different origins

\section{REFERENCES}

Aarestrup, F. M., Butaye, P., and Witte, W. (2002). "Nonhuman reservoirs of enterococci," in The Enterococci: Pathogenesis, Molecular Biology, and Antibiotic Resistance, Chap. 2, eds M. S. Gilmore, D. B. Clewell, P. Courvalin, G. M. Dunny, B. E. Murray, and L. B. Rice (Washington, DC: ASM Press), 55-99.

An, F. Y., and Clewell, D. B. (1997). The origin of transfer (oriT) of the enterococcal, pheromoneresponding, cytolysin plasmid pAD1 is located within the repA determinant. Plasmid 37, 87-94.

Badgley, B. D., Thomas, F. I., and Harwood, V. J. (2010). The effects of submerged aquatic vegetation on the persistence of environmental populations of Enterococcus spp. Environ. Microbiol. 12, 1271-1281.

Baldassarri, L., Bertuccini, L., Ammendolia, M. G., Gherardi, G., and Creti, R. (2001). Variant esp gene in vancomycin-sensitive Enterococcus faecium. Lancet 357, 1802.

Baquero, F. (2004). From pieces to patterns: evolutionary engineering in bacterial pathogens. Nat. Rev. Microbiol. 2, 510-518.

Barrangou, R., Fremaux, C., Deveau, H., Richards, M., Boyaval, P., Moineau, S., Romero, D. A., and Horvath, P. (2007). CRISPR provides acquired resistance against viruses in prokaryotes. Science 315, 1709-1712.

Bates, J. (1997). Epidemiology of vancomycin-resistant enterococci in the community and the relevance of farm animals to human infection. $J$. Hosp. Infect. 37, 89-101.

Bates, J., Jordens, J. Z., and Griffiths, D. T. (1994). Farm animals as a putative reservoir for vancomycinresistant enterococcal infection in man. J. Antimicrob. Chemother. 34, 507-514.

Benno, Y., Izumi-Kurotani, A., and Yamashita, M. (1992). Isolation and identification of intestinal bacteria from Japanese tree frog (Hyla japonica) with the special reference to anaerobic bacteria. J. Vet. Med. Sci. 54, 699-702.

Biavasco, F., Foglia, G., Paoletti, C., Zandri, G., Magi, G., Guaglianone, E., Sundsfjord, A., Pruzzo, C., Donelli, G., and Facinelli, B. (2007). VanAtype enterococci from humans, animals, and food: species distribution, population structure, Tn1546 typing and location, and virulence determinants. Appl. Environ. Microbiol. 73, 3307-3319.

Bonora, M. G., Olioso, D., Lo Cascio, G., and Fontana, R. (2007). Phylogenetic analysis of vancomycinresistant Enterococcus faecium genotypes associated with outbreaks or sporadic infections in Italy. Microb. Drug Resist. 13, 171-177.

Bourgogne, A., Garsin, D. A., Qin, X., Singh, K. V., Sillanpaa, J., Yerrapragada, S., Ding, Y., Dugan-Rocha, S., Buhay, C., Shen, H., Chen, G., Williams, G., Muzny, D., Maadani, A., Fox, K. A., Gioia, J., Chen, L.,

(humans, animals, various environments), it is becoming more evident the role of the mobilome in driving the colonization of new niches and hosts, eventually influencing their evolution.

Mobile genetic elements are important forces of evolution in many bacterial species: the discovery that up to $25 \%$ of the $E$. faecalis V583 genome is made up of exogenous mobile genes, opens the question if this is a limited characteristic or an enterococcal genome character. Important contributions will come from the complete genome sequence comparisons, now more easily obtainable by using next generation sequencing technologies, and probably all these studies will resolve many questions related to the ability of these microorganisms to be, at the same time, host-specific and host-variable, to be harmless and opportunistic pathogens. Furthermore, studies on gene regulation in different hosts and environments, involving, for example, global regulators such as sRNA, will probably give further insight into this flexible group of microorganisms.

\section{ACKNOWLEDGMENTS}

The Authors are indebted to Dr. Manuela Coci for her critical reading of the ms and to Dr. Antony Bridgewood for his language revision. The Authors would like to thank Dr. Gino Mongelli for his technical assistance.

Shang, Y., Arias, C. A., Nallapareddy, S. R., Zhao, M., Prakash, V. P., Chowdhury, S., Jiang, H., Gibbs, R. A., Murray, B. E., Highlander, S. K., and Weinstock, G. M. (2008). Large scale variation in Enterococcus faecalis illustrated by the genome analysis of strain OG1RF. Genome Biol. 9 , R110.

Boyd, D. A., Willey, B. M., Fawcett, D., Gillani, N., and Mulvey, M. R. (2008). Molecular characterization of Enterococcus faecalis N060364 with low-level vancomycin resistance harboring a novel $\mathrm{D}$ Ala-D-Ser gene cluster, vanL. Antimicrob. Agents Chemother. 52, 2667-2672.

Cetinkaya, Y., Falk, P., and Mayhall, C. G. (2000). Vancomycin-resistant enterococci. Clin. Microbiol. Rev. 13, 686-707.

Chang, S., Sievert, D. M., Hageman, J. C., Boulton, M. L., Tenover, F. C., Downes, F. P., Shah, S., Rudrik, J. T., Pupp, G. R., Brown, W. J., Cardo, D., Fridkin, S. K., and Vancomycin-Resistant Staphylococcus aureus Investigative Team. (2003). Infection with vancomycin-resistant Staphylococcus aureus containing the vanA resistance gene. N. Engl. J. Med. 348, 1342-1347.

Choudhury, T., Singh, K. V., Sillanpää, J., Nallapareddy, S. R., and Murray, B. E. (2011). Importance of two Enterococcus faecium loci encoding Gls-like proteins for in vitro bile salts stress response and virulence. J. Infect. Dis. 203, 1147-1154.

Coburn, P. S., Baghdayan, A. S., Dolan, G. T., and Shankar, N. (2007). Horizontal transfer of virulence genes encoded on the Enterococcus faecalis pathogenicity island. Mol. Microbiol. 63, 530-544.

Collins, M. D., Farrow, J. A. E., and Jones, D. (1986). Enterococcus mundtii sp. nov. Int. J. Syst. Bacteriol. 36, 8-12.

Coque, T. M., Willems, R., Cantón, R., Del Campo, R., and Baquero, F. (2002). High occurrence of esp among ampicillin-resistant and vancomycin-susceptible Enterococcus faecium clones from hospitalized patients. J. Antimicrob. Chemother. 50, 1035-1038.

Coque, T. M., Willems R, J., Fortún, J., Top, J., Diz, S., Loza, E., Cantón, R., and Baquero, F. (2005). Population structure of Enterococcus faecium causing bacteremia in a Spanish university hospital: setting the scene for a future increase in vancomycin resistance? Antimicrob. Agents Chemother. 49, 2693-2700.

Courvalin, P. (2006). Vancomycin resistance in Gram-positive cocci. Clin. Infect. Dis. 42(Suppl. 1), S25-S34.

Damborg, P., Top, J., Hendrickx, A. P., Dawson, S., Willems, R. J., and Guardabassi, L. (2009). Dogs are a reservoir of ampicillinresistant Enterococcus faecium lineages associated with human infections. Appl. Environ. Microbiol. 75, 2360-2365. 
de Niederhausern, S., Bondi, M., Messi, P., Iseppi, R., Sabia, C., Manicardi, G., and Anacarso, I. (2011). Vancomycin-resistance transferability from VanA enterococci to Staphylococcus aureus. Curr. Microbiol. 62, 1363-1367.

Deshpande, L. M., Fritsche, T. R., Moet, G. J., Biedenbach, D. J., and Jones, R. N. (2007). Antimicrobial resistance and molecular epidemiology of vancomycin-resistant enterococci from North America and Europe: a report from the SENTRY antimicrobial surveillance program. Diagn. Microbiol. Infect. Dis. 58, 163-170.

Devriese, L. A., Hommez, J., Pot, B., and Haesebrouck, F. (1994). Identification and composition of the streptococcal and enterococcal flora of tonsils, intestines and faeces of pigs. J. Appl. Bacteriol. 77, 31-36.

Domann, E., Hain, T., Ghai, R., Billion, A., Kuenne, C., Zimmermann, K., and Chakraborty, T. (2007). Comparative genomic analysis for the presence of potential enterococcal virulence factors in the probiotic Enterococcus faecalis strain Symbioflor 1. Int. J. Med. Microbiol. 297, 533-539.

Dunny, G., Funk, C., and Adsit, J. (1981). Direct stimulation of the transfer of antibiotic resistance by sex pheromones in Streptococcus faecalis. Plasmid 6, 270-278.

Dunny, G. M., Brown, B. L., and Clewell, D. B. (1978). Induced cell aggregation and mating in Streptococcus faecalis: evidence for a bacterial sex pheromone. Proc. Natl. Acad. Sci. U.S.A. 75, 3479-3483.

Eaton, T. J., and Gasson, M. J. (2002). A variant enterococcal surface protein $\mathrm{Esp}(\mathrm{fm})$ in Enterococcus faecium; distribution among food, commensal, medical, and environmental isolates. FEMS Microbiol. Lett. 216, 269-275.

Fisher, K., and Phillips, C. (2009). The ecology, epidemiology and virulence of Enterococcus. Microbiology 155(Pt 6), 1749-1757.

Fontana, C., Gazzola, S., Cocconcelli, P. S., and Vignolo, G. (2009). Population structure and safety aspects of Enterococcus strains isolated from artisanal dry fermented sausages produced in Argentina. Lett. Appl. Microbiol. 49, 411-414.

Franz, C. M., Huch, M., Abriouel, H., Holzapfel, W., and Gálvez, A. (2011). Enterococci as probiotics and their implications in food safety. Int. J. Food Microbiol. 151, 125-140.

Freitas, A. R., Coque, T. M., Novais, C., Hammerum, A. M., Lester, C. H., Zervos, M. J., Donabedian, S.,
Jensen, L. B., Francia, M. V., Baquero, F., and Peixe, L. (2011). Human and swine hosts share vancomycinresistant Enterococcus faecium $\mathrm{CC} 17$ and CC5 and Enterococcus faecalis CC2 clonal clusters harboring Tn1546 on indistinguishable plasmids. J. Clin. Microbiol. 49, 925-931.

Freitas, A. R., Novais, C., RuizGarbajosa, P., Coque, T. M., and Peixe, L. (2009a). Clonal expansion within clonal complex 2 and spread of vancomycin-resistant plasmids among different genetic lineages of Enterococcus faecalis from Portugal. J. Antimicrob. Chemother. 63, 1104-1111.

Freitas, A. R., Novais, C., RuizGarbajosa, P., Coque, T. M., and Peixe, L. (2009b). Dispersion of multidrug-resistant Enterococcus faecium isolates belonging to major clonal complexes in different Portuguese settings. Appl. Environ. Microbiol. 75, 4904-4908.

Freitas, A. R., Tedim, A. P., Novais, C., Ruiz-Garbajosa, P., Werner, G., Laverde-Gomez, J. A., Cantón, R., Peixe, L., Baquero, F., and Coque, T. M. (2010). Global spread of the hyl(Efm) colonization-virulence gene in megaplasmids of the Enterococcus faecium CC17 polyclonal subcluster. Antimicrob. Agents Chemother. 54, 2660-2665.

Hegstad, K., Mikalsen, T., Coque, T. M., Werner, G., and Sundsfjord, A. (2010). Mobile genetic elements and their contribution to the emergence of antimicrobial resistant Enterococcusfaecalis and Enterococcus faecium. Clin. Microbiol. Infect. 16, 541-554.

Heikens, E., Singh, K. V., Jacques-Palaz, K. D., van Luit-Asbroek, M., Oostdijk, E. A., Bonten, M. J., Murray, B. E., and Willems, R. J. (2011). Contribution of the enterococcal surface protein Esp to pathogenesis of Enterococcus faecium endocarditis. Microbes Infect. 13, 1185-1190.

Heikens, E., van Schaik, W., Leavis, H. L., Bonten, M. J., and Willems, R. J. (2008). Identification of a novel genomic island specific to hospitalacquired clonal complex 17 Enterococcus faecium isolates. Appl. Environ. Microbiol. 74, 7094-7097.

Hidron, A. I., Edwards, J. R., Patel, J., Horan, T. C., Sievert, D. M., Pollock, D. A., Fridkin, S. K., National Healthcare Safety Network Team, and Participating National Healthcare Safety Network Facilities. (2008). NHSN annual update: antimicrobialresistant pathogens associated with healthcare-associated infections: annual summary of data reported to the National Healthcare Safety Network at the Centers for Disease Control and Prevention, 2006-2007. Infect. Control Hosp. Epidemiol. 29, 996-1011.

Horvath, P., and Barrangou, R. (2010). CRISPR/Cas, the immune system of bacteria and archaea. Science 327 167-170.

Hufnagel, M., Koch, S., Creti, R., Baldassarri, L., and Huebner, J. (2004). A putative sugar-binding transcriptional regulator in a novel gene locus in Enterococcus faecalis contributes to production of biofilm and prolonged bacteremia in mice. J. Infect. Dis. 189, 420-430.

Iwen, P. C., Kelly, D. M., Linder, J., Hinrichs, S. H., Dominguez, E. A., Rupp, M. E., and Patil, K. D. (1997). Change in prevalence and antibiotic resistance of Enterococcus species isolated from blood cultures over an 8-year period. Antimicrob. Agents Chemother. 41, 494-495.

Kim, D. S., Singh, K. V., Nallapareddy, S. R., Qin, X., Panesso, D., Arias, C. A., and Murray, B. E. (2010). The fms 21 (pilA)-fms20 locus encoding one of four distinct pili of Enterococcus faecium is harboured on a large transferable plasmid associated with gut colonization and virulence. $J$. Med. Microbiol. 59, 505-507.

Klare, I., Heier, H., Claus, H., Böhme, G., Marin, S., Seltmann, G., Hakenbeck, R., Antanassova, V., and Witte, W. (1995). Enterococcus faecium strains with vanA-mediated high-level glycopeptide resistance isolated from animal foodstuffs and fecal samples of humans in the community. Microb. Drug Resist. 1, 265-272.

Klein, G. (2003). Taxonomy, ecology and antibiotic resistance of enterococci from food and the gastrointestinal tract. Int. J. Food Microbiol. 88, 123-131.

Ko, K. S., Baek, J. Y., Lee, J. Y., Oh, W. S., Peck, K. R., Lee, N., Lee, W. G., Lee, K., and Song, J. H. (2005). Molecular characterization of vancomycinresistant Enterococcus faecium isolates from Korea. J. Clin. Microbiol. 43, 2303-2306.

Larsen, J., Schonheyder, H. C., Lester, C. H., Olsen, S. S., Porsbo, L. J., GarciaMigura, L., Jensen, L. B., Bisgaard, M., and Hammerum, A. M. (2010). Porcine-origin gentamicin-resistant Enterococcus faecalis in humans, Denmark. Emerging Infect. Dis. 16, 682-684.

Laverde Gomez, J. A., Hendrickx, A. P., Willems, R. J., Top, J., Sava, I., Huebner, J., Witte, W., and Werner, G. (2011a). Intra- and interspecies genomic transfer of the Enterococcus faecalis pathogenicity island. PLoS ONE 6, e16720. doi:10.1371/journal.pone.0016720

Laverde Gomez, J. A., van Schaik, W. Freitas, A. R., Coque, T. M., Weaver, K. E., Francia, M. V., Witte, W., and Werner, G. (2011b). A multiresistance megaplasmid pLG1 bearing a hylEfm genomic island in hospital Enterococcus faecium isolates. Int. J. Med. Microbiol. 301, 165-175.

Leavis, H., Top, J., Shankar, N., Borgen, K., Bonten, M., van Embden, J., and Willems, R. J. (2004). A novel putative enterococcal pathogenicity island linked to the esp virulence gene of Enterococcus faecium and associated with epidemicity. $J$. Bacteriol. 186, 672-682.

Leavis, H. L., Bonten, M. J., and Willems, R. J. (2006a). Identification of high-risk enterococcal clonal complexes: global dispersion and antibiotic resistance. Curr. Opin. Microbiol. 9, 454-460.

Leavis, H. L., Willems, R. J., Top, J., and Bonten, M. J. (2006b). Highlevel ciprofloxacin resistance from point mutations in gyrA and parC confined to global hospital-adapted clonal lineage CC17 of Enterococcus faecium. J. Clin. Microbiol. 44, 1059-1064.

Leavis, H. L., Willems, R. J., van Wamel, W. J., Schuren, F. H., Caspers, M. P., and Bonten, M. J. (2007). Insertion sequence-driven diversification creates a globally dispersed emerging multiresistant subspecies of E. faecium. PLoS Pathog. 3, e7. doi:10.1371/journal.ppat.0030007

Lebreton, F., Depardieu, F., Bourdon, N., Fines-Guyon, M., Berger, P., Camiade, S., Leclercq, R., Courvalin, P., and Cattoir, V. (2011). DAla-D-Ser VanN-Type transferable vancomycin resistance in Enterococcus faecium. Antimicrob. Agents Chemother. 55, 4606-4612.

Malachowa, N., and DeLeo, F. R. (2010). Mobile genetic elements of Staphylococcus aureus. Cell. Mol. Life Sci. 67, 3057-3071.

Manson, J. M., Hancock, L. E., and Gilmore, M. S. (2010). Mechanism of chromosomal transfer of Enterococcus faecalis pathogenicity island, capsule, antimicrobial resistance, and other traits. Proc. Natl. Acad. Sci. U.S.A. 107, 12269-12274.

Marraffini, L. A., and Sontheimer, E. J. (2008). CRISPR interference limits horizontal gene transfer in staphylococci by targeting DNA. Science 322, 1843-1845.

Marraffini, L. A., and Sontheimer, E. J. (2010). CRISPR interference: RNA-directed adaptive immunity 
in bacteria and archaea. Nat. Rev. Genet. 11, 181-190.

McBride, S. M., Coburn, P. S., Baghdayan, A. S., Willems, R. J., Grande, M. J., Shankar, N., and Gilmore, M. S. (2009). Genetic variation and evolution of the pathogenicity island of Enterococcus faecalis. J. Bacteriol. 191, 3392-3402.

McBride, S. M., Fischetti, V. A., Leblanc, D. J., Moellering, R. C. Jr., and Gilmore, M. S. (2007). Genetic diversity among Enterococcus faecalis. PLoS ONE 2, e582. doi:10.1371/journal.pone.0000582

Mohamed, J. A., Huang, W., Nallapareddy, S. R., Teng, F., and Murray, B. E. (2004). Influence of origin of isolates, especially endocarditis isolates, and various genes on biofilm formation by Enterococcus faecalis. Infect. Immun. 72, 3658-3663.

Nallapareddy, S. R., Singh, K. V., Sillanpää, J., Zhao, M., and Murray, B. E. (2011). Relative contributions of Ebp Pili and the collagen adhesin ace to host extracellular matrix protein adherence and experimental urinary tract infection by Enterococcus faecalis OG1RF. Infect. Immun. 79, 2901-2910.

Nieto-Arribas, P., Sesena, S., Poveda, J. M., Chicón, R., Cabezas, L., and Palop, L. (2011). Enterococcus populations in artisanal Manchego cheese: biodiversity, technological and safety aspects. Food Microbiol. 28, 891-899.

NNIS. (2004). National Nosocomial Infections Surveillance (NNIS) system report, data summary from January 1992 through June 2004, issued October 2004. Am. J. Infect. Control 32, 470-485.

Novais, C., Freitas, A. R., Sousa, J. C., Baquero, F., Coque, T. M., and Peixe, L. V. (2008). Diversity of Tn1546 and its role in the dissemination of vancomycin-resistant enterococci in Portugal. Antimicrob. Agents Chemother. 52, 1001-1008.

Palmer, K. L., Carniol, K., Manson, J. M., Heiman, D., Shea, T., Young, S., Zeng, Q., Gevers, D., Feldgarden, M., Birren, B., and Gilmore, M. S. (2010a). High-quality draft genome sequences of 28 Enterococcus sp. isolates. J. Bacteriol. 192, 2469-2470.

Palmer, K. L., Kos, V. N., and Gilmore, M. S. (2010b). Horizontal gene transfer and the genomics of enterococcal antibiotic resistance. Curr. Opin. Microbiol. 13, 632-639.

Palmer, K. L., and Gilmore, M. S. (2010). Multidrug-resistant enterococci lack CRISPR-cas. MBio 1, e00227-10.

Panesso, D., Montealegre, M. C., Rincón, S., Mojica, M. F., Rice,
L. B., Singh, K. V., Murray, B. E., and Arias, C. A. (2011). The hylEfm gene in pHylEfm of Enterococcus faecium is not required in pathogenesis of murine peritonitis. BMC Microbiol. 11, 20. doi:10.1186/1471-2180-11-20

Paulsen, I. T., Banerjei, L., Myers, G. S., Nelson, K. E., Seshadri, R., Read, T. D., Fouts, D. E., Eisen, J. A., Gill, S. R., Heidelberg, J. F., Tettelin, H., Dodson, R. J., Umayam, L., Brinkac, L., Beanan, M., Daugherty, S., DeBoy, R. T., Durkin, S., Kolonay, J., Madupu, R., Nelson, W., Vamathevan, J., Tran, B., Upton, J., Hansen, T., Shetty, J., Khouri, H., Utterback, T., Radune, D., Ketchum, K. A., Dougherty, B. A., and Fraser, C. M. (2003). Role of mobile DNA in the evolution of vancomycin-resistant Enterococcus faecalis. Science 299, 2071-2074.

Perichon, B., and Courvalin, P. (2004). Heterologous expression of the enterococcal vanA operon in methicillin-resistant Staphylococcus aureus. Antimicrob. Agents Chemother. 48, 4281-4285.

Pinkston, K. L., Gao, P., Diaz-Garcia, D., Sillanpää, J., Nallapareddy, S. R., Murray, B. E., and Harvey, B. R. (2011). The Fsr quorum-sensing system of Enterococcus faecalis modulates surface display of the collagenbinding MSCRAMM Ace through regulation of gelE. J. Bacteriol. 193, 4317-4325.

Quednau, M., Ahrne, S., Petersson, A. C., and Molin, G. (1998). Identification of clinically important species of Enterococcus within 1 day with randomly amplified polymorphic DNA (RAPD). Curr. Microbiol. 36, 332-336.

Rice, L. B., Carias, L., Rudin, S., Vael, C., Goossens, H., Konstabel, C., Klare, I., Nallapareddy, S. R., Huang, W., and Murray, B. E. (2003). A potential virulence gene, hylEfm, predominates in Enterococcus faecium of clinical origin. J. Infect. Dis. 187, 508-512.

Rice, L. B., and Carias, L. L. (1998). Transfer of Tn5385, a composite, multiresistance chromosomal element from Enterococcus faecalis. J. Bacteriol. 180, 714-721.

Rice, L. B., Hutton-Thomas, R., Lakticova, V., Helfand, M. S., and Donskey, C. J. (2004). Beta-lactam antibiotics and gastrointestinal colonization with vancomycin-resistant enterococci. J. Infect. Dis. 189, 1113-1118.

Rich, R. L., Kreikemeyer, B., Owens, R. T., LaBrenz, S., Narayana, S. V., Weinstock, G. M., Murray, B. E., and Höök, M. (1999). Ace is a collagen-binding MSCRAMM from
Enterococcus faecalis. J. Biol. Chem. 274, 26939-26945.

Roberts, A. P., and Mullany, P. (2009). A modular master on the move: the Tn916 family of mobile genetic elements. Trends Microbiol. 17, 251-258.

Rosenthal, V. D., Maki, D. G., Mehta, A., Alvarez-Moreno, C., Leblebicioglu, H., Higuera, F., Cuellar, L. E., Madani, N., Mitrev, Z., Dueñas, L. Navoa-Ng, J. A., Garcell, H. G., Raka, L., Hidalgo, R. F., Medeiros, E. A., Kanj, S. S., Abubakar, S., Nercelles, P., Pratesi, R. D., and International Nosocomial Infection Control Consortium Members. (2008). International Nosocomial Infection Control Consortium report, data summary for 2002-2007, issued January 2008. Am. J. Infect. Control 36, 627-637.

Rosvoll, T. C., Pedersen, T., Sletvold, H. Johnsen, P. J., Sollid, J. E., Simonsen, G. S., Jensen, L. B., Nielsen, K. M., and Sundsfjord, A. (2010). PCRbased plasmid typing in Enterococcus faecium strains reveals widely distributed pRE25-, pRUM-, pIP501and pHTbeta-related replicons associated with glycopeptide resistance and stabilizing toxin-antitoxin systems. FEMS Immunol. Med. Microbiol. 58, 254-268.

Sarti, M., Campanile, F., Sabia, C., Santagati, M., Gargiulo, R., and Stefani, S. (2012). Polyclonal diffusion of Beta-lactamase-producing Enterococcus faecium. J. Clin. Microbiol. 50, 169-172.

Sarti, M., Campanile, F., Sabia, C., Santagati, M., Scuderi, C., Gargiulo, R., and Stefani, S. (2011). "Isolation and identification of Beta-lactamase in polyclonal clinical isolates of Enterococcus faecium," in 51st Interscience Conference on Antimicrobial Agents and Chemotherapy, Chicago, IL.

Sava, I. G., Heikens, E., Kropec, A. Theilacker, C., Willems, R., and Huebner, J. (2010). Enterococcal surface protein contributes to persistence in the host but is not a target of opsonic and protective antibodies in Enterococcus faecium infection. J. Med. Microbiol. 59, 1001-1004.

Schluter, S., Franz, C. M., Gesellchen, F., Bertinetti, O., Herberg, F. W., and Schmidt, F. R. (2009). The high biofilm-encoding Bee locus: a second pilus gene cluster in Enterococcus faecalis? Curr. Microbiol. 59, 206-211.

Shankar, N., Baghdayan, A. S., and Gilmore, M. S. (2002). Modulation of virulence within a pathogenicity island in vancomycin-resistant Enterococcus faecalis. Nature 417, 746-750.
Shankar, N., Coburn, P., Pillar, C., Haas, W., and Gilmore, M. (2004). Enterococcal cytolysin: activities and association with other virulence traits in a pathogenicity island. Int. J. Med. Microbiol. 293, 609-618.

Shepard, B. D., and Gilmore, M. S. (2002). Antibiotic-resistant enterococci: the mechanisms and dynamics of drug introduction and resistance. Microbes Infect. 4, 215-224.

Shioya, K., Michaux, C., Kuenne, C., Hain, T., Verneuil, N., BudinVerneuil, A., Hartsch, T., Hartke, A., and Giard, J. C. (2011) Genome-wide identification of small RNAs in the opportunistic pathogen Enterococcus faecalis V583. PLoS ONE 6, e23948. doi:10.1371/journal.pone.0023948

Sieradzki, K., Roberts, R. B., Haber, S. W., and Tomasz, A. (1999). The development of vancomycin resistance in a patient with methicillin-resistant Staphylococcus aureus infection. N. Engl. J. Med. 340, 517-523.

Sillanpää, J., Nallapareddy, S. R., Singh, K. V., Prakash, V. P., Fothergill, T., Ton-That, H., and Murray, B. E. (2010). Characterization of the $\mathrm{ebp}(\mathrm{fm})$ pilus-encoding operon of Enterococcus faecium and its role in biofilm formation and virulence in a murine model of urinary tract infection. Virulence 1, 236-246.

Singh, K. V., Coque, T. M., Weinstock, G. M., and Murray, B. E. (1998). In vivo testing of an Enterococcus faecalis efaA mutant and use of efaA homologs for species identification. FEMS Immunol. Med. Microbiol. 21, 323-331.

Singh, K. V., Nallapareddy, S. R., Nannini, E. C., and Murray, B. E. (2005). Fsr-independent production of protease(s) may explain the lack of attenuation of an Enterococcus faecalis fsr mutant versus a gelE-sprE mutant in induction of endocarditis. Infect. Immun. 73, 4888-4894.

Solheim, M., Brekke, M. C., Snipen, L. G., Willems, R. J., Nes, I. F., and Brede, D. A. (2011). Comparative genomic analysis reveals significant enrichment of mobile genetic elements and genes encoding surface structure-proteins in hospitalassociated clonal complex 2 Enterococcus faecalis. BMC Microbiol. 11, 3 . doi:10.1186/1471-2180-11-13

Srinivasan, A., Dick, J. D., and Perl, T. M. (2002). Vancomycin resistance in staphylococci. Clin. Microbiol. Rev. $15,430-438$.

Tannock, G. W., and Cook, G. (2002). "Enterococci as members of the intestinal microflora of humans," in 
The Enterococci: Pathogenesis, Molecular Biology, and Antibiotic Resistance, Chap. 3, eds M. S. Gilmore, D. B. Clewell, P. Courvalin, G. M. Dunny, B. E. Murray, and L. B. Rice (Washington, DC: ASM Press), 101-132.

Tarasova, E., Yermolenko, E., Donets, V., Sundukova, Z., Bochkareva, A., Borshev, I., Suvorova, M., Ilyasov, I., Simanenkov, V., and Suvorov, A. N. (2010). The influence of probiotic Enterococcus faecium strain L5 on the microbiota and cytokines expression in rats with dysbiosis induced by antibiotics. Benef. Microbes 1, 265-270.

Tendolkar, P. M., Baghdayan, A. S., and Shankar, N. (2006). Putative surface proteins encoded within a novel transferable locus confer a high-biofilm phenotype to Enterococcus faecalis. J. Bacteriol. 188, 2063-2072.

Tenover, F. C., Biddle, J. W., and Lancaster, M. V. (2001). Increasing resistance to vancomycin and other glycopeptides in Staphylococcus aureus. Emerging Infect. Dis. 7, 327-332.

Top, J., Willems, R., Blok, H., de Regt, M., Jalink, K., Troelstra, A., Goorhuis, B., and Bonten, M. (2007). Ecological replacement of Enterococcus faecalis by multiresistant clonal complex 17 Enterococcus faecium. Clin. Microbiol. Infect. 13, 316-319.

Top, J., Willems, R., van der Velden, S., Asbroek, M., and Bonten, M. (2008). Emergence of clonal complex 17 Enterococcus faecium in The Netherlands. J. Clin. Microbiol. 46, 214-219.

Treitman, A. N., Yarnold, P. R., Warren, J., and Noskin, G. A. (2005). Emerging incidence of Enterococcus faecium among hospital isolates (1993 to 2002). J. Clin. Microbiol. 43, 462-463.
Uttley, A. H., Collins, C. H., Naidoo, J., and George, R. C. (1988). Vancomycin-resistant enterococci. Lancet 1, 57-58.

van den Bogaard, A. E., Bruinsma, N., and Stobberingh, E. E. (2000). The effect of banning avoparcin on VRE carriage in The Netherlands. J. Antimicrob. Chemother. 46, 146-148. van Schaik, W., Top, J., Riley, D. R., Boekhorst, J., Vrijenhoek, J. E., Schapendonk, C. M., Hendrickx, A. P., Nijman, I. J., Bonten, M. J., Tettelin, H., and Willems, R. J. (2010). Pyrosequencing-based comparative genome analysis of the nosocomial pathogen Enterococcus faecium and identification of a large transferable pathogenicity island. BMC Genomics 11, 239. doi:10.1186/1471-2164-11-239

van Schaik, W., and Willems, R. J. (2010). Genome-based insights into the evolution of enterococci. Clin. Microbiol. Infect. 16, 527-532.

Vaughn, D. H., Riggsby, W., and Mundt, J. O. (1979). Deoxyribonucleic acid relatedness of strains of yellow-pigmented, group D streptococci. Int. J. Syst. Bacteriol. 29, 204-212.

Weigel, L. M., Clewell, D. B., Gill, S. R., Clark, N. C., McDougal, L. K., Flannagan, S. E., Kolonay, J. F., Shetty, J., Killgore, G. E., and Tenover, F. C. (2003). Genetic analysis of a highlevel vancomycin-resistant isolate of Staphylococcus aureus. Science 302, 1569-1571.

Werner, G., Coque, T. M., Hammerum, A. M., Hope, R., Hryniewicz, W., Johnson, A., Klare, I., Kristinsson, K. G., Leclercq, R., Lester, C. H., Lillie, M., Novais, C., Olsson-Liljequist, B., Peixe, L. V., Sadowy, E., Simonsen, G. S., Top, J., Vuopio-Varkila, J., Willems, R. J., Witte, W., and Woodford, N. (2008). Emergence and spread of vancomycin resistance among enterococci in Europe. Euro Surveill. 13, pii: 19046.

Werner, G., Klare, I., and Witte, W. (2007). The current MLVA typing scheme for Enterococcus faecium is less discriminatory than MLST and PFGE for epidemicvirulent, hospital-adapted clonal types. BMC Microbiol. 7, 28. doi:10.1186/1471-2180-7-28

Willems, R. J., Homan, W., Top, J., van Santen-Verheuvel, M., Tribe, D., Manzioros, X., Gaillard, C., Vandenbroucke-Grauls, C. M. Mascini, E. M., van Kregten, E., van Embden, J. D., and Bonten, M. J. (2001). Variant esp gene as a marker of a distinct genetic lineage of vancomycinresistant Enterococcus faecium spreading in hospitals. Lancet 357, 853-855.

Willems, R. J., Top, J., van Den Braak, N., van Belkum, A., Endtz, H., Mevius, D., Stobberingh, E., van Den Bogaard, A., and van Embden, J. D. (2000). Host specificity of vancomycin-resistant Enterococcus faecium. J. Infect. Dis. 182, 816-823.

Willems, R. J., Top, J., van den Braak, N., van Belkum, A., Mevius, D. J., Hendriks, G., van Santen-Verheuvel, M., and van Embden, J. D. (1999). Molecular diversity and evolutionary relationships of Tn1546-like elements in enterococci from humans and animals. Antimicrob. Agents Chemother. 43, 483-491.

Willems, R. J., Top, J., van Santen, M., Robinson, D. A., Coque, T. M., Baquero, F., Grundmann, H., and Bonten, M. J. (2005). Global spread of vancomycin-resistant Enterococcus faecium from distinct nosocomial genetic complex. Emerging Infect. Dis. 11, 821-828.

Willems, R. J., and van Schaik, W. (2009). Transition of
Enterococcus faecium from commensal organism to nosocomial pathogen. Future Microbiol. 4, 1125-1135.

Woodford, N., Soltani, M., and Hardy, K. J. (2001). Frequency of esp in Enterococcus faecium isolates. Lancet 358, 584.

Zheng, B., Tomita, H., Inoue, T., and Ike, Y. (2009). Isolation of VanB-type Enterococcus faecalis strains from nosocomial infections: first report of the isolation and identification of the pheromone-responsive plasmids pMG2200, encoding VanB-type vancomycin resistance and a Bac41-type bacteriocin, and pMG2201, encoding erythromycin resistance and cytolysin (Hly/Bac) Antimicrob. Agents Chemother. 53, 735-747.

Conflict of Interest Statement: The authors declare that the research was conducted in the absence of any commercial or financial relationships that could be construed as a potential conflict of interest.

Received: 27 October 2011; accepted: 27 February 2012; published online: 14 March 2012.

Citation: Santagati M, Campanile F and Stefani S (2012) Genomic diversification of enterococci in hosts: the role of the mobilome. Front. Microbio. 3:95. doi: 10.3389/fmicb.2012.00095

This article was submitted to Frontiers in Antimicrobials, Resistance and Chemotherapy, a specialty of Frontiers in Microbiology.

Copyright (C) 2012 Santagati, Campanile and Stefani. This is an open-access article distributed under the terms of the Creative Commons Attribution Non Commercial License, which permits noncommercial use, distribution, and reproduction in other forums, provided the original authors and source are credited. 